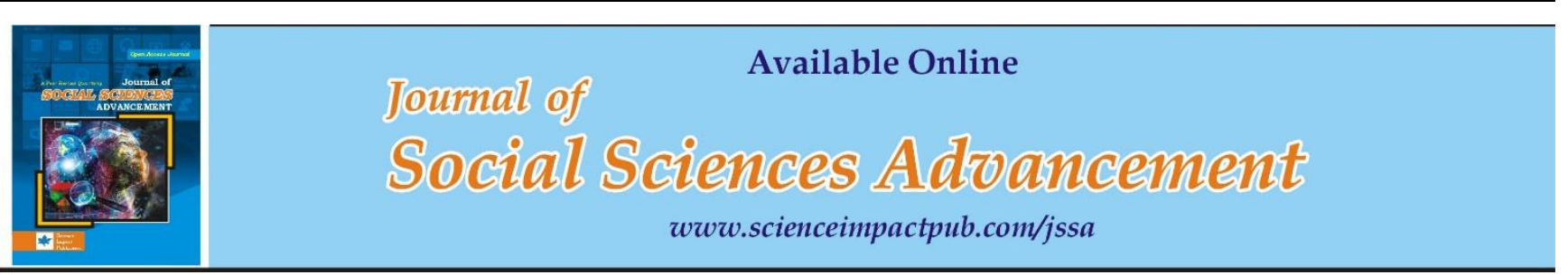

\title{
PRACTICAL PROBLEMS PLAGUING LOW QUALITY EDUCATION AND STEPS NEEDED FOR INVESTMENT IN PUBLIC SCHOOLS OF PAKISTAN
}

\author{
Khalida Parveen ${ }^{1}$ and Phuc Quang Bao Tran ${ }^{1}$ \\ ${ }^{1}$ Faculty of Education, Southwest University, Chongqing, China
}

\begin{abstract}
The concepts, students gained at school level assist in considering advance form of these conceptions at higher education level. Pakistan being a developing country suffering from low quality at school levels. There are many factors responsible for this condition. Teachers' proficiency, basic facilities and curriculum are the basic elements of quality education. In Pakistan all these elements are criticized on different forums. Though Pakistan Government is struggling to get rid of these problems to ensure quality in educational system. To meet this objective, and to exploit internal and external resources, different initiatives are taken by government of Pakistan. Currently, Quality education is dire demand of the day. Advancement is contingent to educational quality. Only means of the existence in globalization is quality education. Yet quality cannot be shown to someone as concrete object. It can only be achieved by providing proper facilities, well trained teachers and comprehensive learning materials. In the dearth of one of these facilities, quality education is not possible. That is why, Pakistan Government is ensuring for the provision of quality standards. For this purpose government is consuming not only all internal (local) and external (international) means and human resources also. But some problems slow down this development process and these are hurdles in this way. To remove these barriers Government of Pakistan has fixed some priorities i.e. enhancement of budget to facilitate the schools, revision of curriculum, teachers professional development and allocation of more funds for the development of needy students. In spite of these efforts many more are to be required yet. Some considerable steps are: (i) Professional elaboration of organizers, principals and other staff members (ii) Formation of Evaluation Committee through associating incentives and grants (iii) District wise planning and application of plans (iv) increase in salaries on teachers (v) provision of science and computer labs.
\end{abstract}

Keywords: Quality education; students achievement; Low quality; physical and learning resources; supervision, infrastructure

Corresponding Author: Khalida Parveen, Email: nicepak81@hotmail.com

(C) The Author(s) 2020

\section{INTRODUCTION}

Education is basic phase for human resource development. Quality education supports creative community and produce opportunities for economically and communally deprived sectors of society. Education emphasizes to learning progression which involves life experiences, knowledge, values and skills are transmitted from one to the next generation by development, research, teaching and training that contribute to socio-economic advancement of country (Ministry of Finance, 2013). Education is considered as a determining factor of human assets, it is also viewed as significant factor for economic development. Socialists and educationists have been taking interest regarding the role of capital in public education for the students' performance (Hanushek, 2002). To condense the inequality of earnings and to enhance the social flexibility among middle and poor earning families, an extensive approach to public education has been observed (Hathaway, 2005). A well standard public education produce means for deprived youth. It is demonstrated that school funding facilitate students belong to lower areas to get rid of poverty and to earn better income (Leask, 2004). In short, public education is the source to get equity and efficiency and to meet social goals.

Presently, public education is financed by provincial government. A large part of budget is fixed to spend on noninstructional matters, like building, furniture and other infrastructure. But the instructional matters are ignored while setting budget. But unfortunately additional spending on students behalf and students achievement is nearly very small or zero (Hanushek, 2002).

\section{Statement of problem}

Various studies had been conducted to check and explore the hurdles in the way of quality education. Most of the previous literature talked about only physical non-instructional facilities. It is reality that non-instructional facilities and work is important for a good educational environment but instructional matters almost been ignored. It seems that per pupil funding in all states of Pakistan is nearly zero. A trial for this literature is, whether is there need to 
facilitate the students with funding by government and how this fund effects the students achievement in public schools of public schools of Pakistan. Another purpose to fix this literature is to test whether or not students at the lowest and highest levels of achievement distribution are influenced by budget increase uniformly or alternatively. This rapid growth is also effecting school and teaching quality. Unsurprisingly urban areas of Punjab need more schools. Already existing schools also need more funds to improve quality. It needs more buildings, more facilities and capacities.

\section{Significance of Quality education}

It is obvious that if a country want to prepare the students to cope with the tasks and challenges of global market, quality education is indispensable for this purpose. School education is censured from many years that it has low quality and is failed to produce students with no understanding of fundamental concepts. These students cannot find opportunities in market because of gap between job demands and supply of skills. Hussain (2005) described that this mismatch and gap between demands of job and supply of skills. This also causes misallocation of resources and deficiency of needed skills which move the economy wheel continue.

It is significant to improve all phases of quality education and to ensure distinction of all because measureable and recognized learning results are attained by it. Especially in numeracy, literacy and fundamental life talents (Article 7 (vi) states quality as an art of monitoring, planning, coordination and control. Furthermore, Gandhe (2010), reflects the quality of education as pattern of advanced and improved standards i.e. suitability for purpose, worth for money and excellence \& stability.

Dill (2013) indicates that "educational quality is vague, too ambiguous and non-measurable in short is not proper for public parameters." Beaton (1999) pointed out that the "affectation of educational quality is seldom imprecise. Pounder (1999) argues that quality is a "particularly confusing term. So quality of education is resolute at basic education and elementary level. It organizes the persons for various educational intensities and trains them with significant life assistance (Ahmad, 2009).

\section{According to UNESCO (2003)}

Mostly people interpreted the quality of education as students learning result which is the most important and key point of all practitioners. Now for the achievement of desired quality the ancestors viewed about the process which leads to quality regarding excellence, social justice, effectiveness and efficiency. The out of quality education can be attained only if the quality is certified at every phase and each level in educational process from prevailing situation, teacher training, learning environment, assessment \& evaluation and teaching-learning practices.

\section{Current scenario of quality education in Pakistan}

The upmost significant element that effects the young generation and country's future, is approach to quality education. The access and quality of level of education, are the foremost powers to be useful for Pakistan to accomplish great social and financial improvement (Saultz \& Saultz, 2017). As per the National Education policy (2009) it is elusive to define quality but there will be need to draw some parameters. There is an imminent demand to discuss and willing on what set up excellence at educational system and at all stages of education. From the foundation of Pakistan, Government showed considerable significance of education. An educational conference held by Government of Pakistan was organized in Karachi quite later its foundation in 1947 and it was described that the educational national system should be grounded on the durable basis of compulsory and free primary education.

The National Education Commission (1959) predicted that Pakistan educational system should encounter the collective and individual requirements and desires of the common people. Afterwards, according to the reports on elementary education of National Education Policy (1992) and The World Bank (1997), the greatest approach to advance access is improving quality. It ensures coming and staying at school. Furthermore, efforts to expand quality will build the productivity and competence of communal expenses and will boost parents to sponsor the education of their children.

\section{FACTORS RESPONSIBLE FOR LOW QUALITY Financial problems - lack of capital}

Education is being ignored regarding government financial support for a long time. Current situation of spending only $2 \%$ of GDP budget on education is condemnable. The educational sector is rendered as unappealing profession in Pakistan. Financial condition of teachers is poor; they are less paid compared with employees of other professions. Teachers are compelled to look for other sources of earning money due to poor financial condition and at their professional integrity cost. (Zafar, 2003). Teachers are not able to spend a contented life within the pay amount, offered to them by government. This cause has decreased the teachers' motivation. That is why, teachers could not pay attention and concentrate on their work and job. This diverse situation has eventually compressed the entire quality of teaching learning process in schools. The teacher absenteeism ratio high in government institutes. Most of the teachers have to run their part time businesses with their teaching profession (Shahzadi and Perveen, 2002). Another example, Ahmad (2009) stated that capital and physical condition definitely influence the 
learning outcomes of the students. As students achievement depends on the advancement of instructional and noninstructional work.

\section{Lack of physical and learning resources}

Audio visual aids and other physical learning material is important for the advancement of teaching learning environment. Most of the schools in Pakistan do not have full accessories and lack of basic aids. Even some school are without sufficient class rooms, library and laboratory equipment. Playground for students are also not available which are compulsory for physical activities and for the development of students (Qureshi, 2002). Lack of physical resources also effects the motivation and efficiency teachers. They are unable to provide wider and advanced chances for the development and learning of their students. Teachers are considered responsible for completion of course in time so in this situation teachers cannot perform their duty well and they failed to produce functionality and learning environment in schools (Hussain, 2005).

\section{Lack of strong supervision}

As per the views of Dill (2003) supervision and leadership in Pakistani schools is also a big hurdle in the way of development and to bring quality in public schools. Bureaucracy plays its role behind the supervision and effects the foundations of management and administration. The real objective of the supervision is to work for the development of students and teachers and for the betterment of school objectives. On the other hand, the practice of supervision is considered the joined with the inspection in Pakistan. A fear is created in the minds of teachers in the supervision process. (Mohanty, 2007). Supervisors behaviors is just like kings and the teachers are considered like inferiors and slaves. Due to this behavior teachers feel discouragement and mistrust during their stay. Supervisors and principals adopt autocratic leadership styles instead of democratic styles so teachers cannot get constructive feedback. Thus quality and improvement effects a lot and no perfection takes place (Khan, 1990). Most educational scholars and school administrators are much interested in the quality of education but pay little attention to the effectiveness of school leadership. It is due to the fact assessing leadership effectiveness depends on many influential factors and collaboration of many resources in society. This research purposefully investigates school leaders' level of leadership effectiveness in correlation with leadership competencies and styles, which are basically derived from their knowledge, qualities, skills, and experiences.

\section{Curriculum issues}

It is considered a centralized activity to develop an effective and up to date curriculum. Curriculum should be made according to the needs of the pupils and meeting our national goals and schools objectives. Curriculum implementers are teachers who play their role made it effective and ensure to convey instructions to their students. Teachers are bound to follow only on instructions Dill of curriculum and cannot contribute on their own during the process of curriculum setting (Hoodbhoy, 1998). In this way, teachers are left ignorant about the curriculum settings which ultimately disturbs the performance of teachers. Besides it, at certain levels teachers are not well aware with the goals and aims of the curriculum. This situation is a big gap in understating and effective implementation of curriculum. Changing of medium of instruction in English and Urdu is also a big hurdle in the way of quality. Teachers should be involved in the process of curriculum design and development. It is compulsory to involve the end users in the process of direction and development of the system. It is also an important factor responsible for the low quality of the education system (Government of Pakistan, 2001).

\section{Issues of text books}

Text books are considered a significant part of curriculum. Curriculum is one of the fundamental sources to facilitate chances for enhancement and perfection of new knowledge and reading for beginners. Development of textbooks is a particular area in the development of curriculum. A textbook is a necessary component of education as it is one of the basic sources of content (Farooq, 1994). School teachers face many problems in giving instructions due to poor quality and non-availability of textbooks. Multi-medium of instructions is a culture in Pakistani schools which confuses the students and as well as teachers also. In addition, teachers are not given proper training about to explain and facilitate students to understand different textbooks (Hussain, 2005). Definitely, it's the reason, for the low and poor quality of schools.

\section{Insufficient Evaluation}

As per (OECD , 2005; 2006a; 2008d) evaluation plays a key role in quality process and improvement of school development (OECD , 2005; 2006a; 2008d) and Plank \& Smith (2008) as cited by Blackburn (2015). Evaluation is an activity of detecting potencies and limitations of a process and organization. In recent times, the objective of evaluation has been transformed in many states. Historically, its focus was on the school monitoring with the purpose to ensure that whether the schools are running according to the procedures and school policies properly and look after other administrative issues. Now the evaluation has been transformed from traditional to school development contrivance. School assessment and evaluation is an indispensable chore of educational administration and works for various commitments like; to fulfill legal responsibility purposes, to fulfill organizational demands; and works for administrative and educational development (Grauwe \& Naidoo, 2014). So evaluation assists two intertwined commitments; accountability and improvement. Moreover, school assessment 
and evaluation is needed to reduce the gap between the low achievement high performances of schools, it also enhances the outcomes and achievements of the students. Evaluation and assessment process are not adequate to get appropriate results.

\section{Lack of Teachers professional development}

In the absence of good teachers, quality cannot be achieved as teachers are the most vital component of the administration system of a country. It is obvious that quality education is possible only by getting services of competent teachers. As per guidelines of National Education Commission (1959) "No education system is better than its teachers". According to Memon (2007) teachers are the best serious factor of educational system. If the teachers are not well trained and have PD, teachers cannot give concentration to their duty. Association for Teacher Education in Europe (2006) defines in a paper namely "the quality of teachers" that teachers quality impacts the learning of student and the quality of teaching and learning in schools. As per Akram et al., (2020) there is not adequate training and guidance from the principals.

Moreover, teachers are estimated to establish innovative role as a component of the logical improvement. Teachers professional development establish room for teacher to reconnoiter new innovations, new pedagogical technique, enhance their performance and extend themselves both in professional sphere and individual skills (Alkhyeli, 2018). It is essential to all educational stake holders and educational communities had better to understand the different hope of the teachers, the new administration characters as well as the duty \&and existing description of professional development, credit by all-inclusive community of the composite nature of the changes needed is the first step in creating necessary management practices that enables teachers fulfill their fundamental role in organized reforms (Beltman, 2016). Conversely schools are organizational and un-orthodox, teachers are out-of-theway as one another and to some extent knowledgeable to fulfill their responsibility independently. School Management typically assists to promote teamwork. PD takes depend upon a deficit model in which teachers who participate in professional program weights data and info to teachers who are expected to be incomplete and in requirement of external specialists to impart them up-to-date approaches of occupied with learners (Mayer, 2001). Likewise principals are also facing various challenges in improving quality of public schools and teachers professional development also is a remarkable reason out of them (Parveen et. al., 2021).

\section{Infrastructure}

Numerous basic facilities like school laboratories, school building, libraries, electricity, toilets and drinking water are requirements for brining quality in education. Education is always poor and low level without these necessities of education and for quality education, these amenities are obligatory (Alkhyeli, 2018).

\section{EFFECTS OF LOW QUALITY EDUCATION IN PAKISTAN}

The excellence of school environment and the ability of teaching work force impacts pupils learning by education and guidance of students which occurs in the classrooms, and through the workout accomplished at school premises. The aspects responsible for school excellence have direct and indirect impact on students' achievement and outcomes. The features of school settings i.e. leadership and non-instructional facilities can affect the teachers functioning in classroom as well as the achievement and learning of students. Moreover, different traits of teachers can also have impact the quality of the activities and student outcomes. These all teacher level attributes can contribute directly in acquiring knowledge (Mayer, Mullens \& Moore, 2001).

To achieve communal goals, how a leader influences a group, is called leadership (Ataliç, 2016). To improve teacher morale, certain practices of leadership have been shown to be valuable such as good communication with teachers, establishing relationship between the principals and teachers and creating professionalism in teachers (Beltman et al., 2016). The principals who gave appreciation while showing interpersonal skills, facilitated their teachers with good morale (Blackburn, 2015). Alkhyeli \& Van Ewijk (2018) discussed in another study that many factors are associated with satisfaction of work and took notice of the styles of leaders on teachers job satisfaction.

Atalic (2016) described that safe working environment, good interpersonal relations, salary structures, organizational policies, fair administration, job security, employee support, workers rights, benefits are included in hygiene and these factors. To promote the employee motivation; maintenance factors, dis-satisfiers and hygiene factors are effective. Although these factors do not always create long term contentment but there could be discontentment in their absence. Saultz \& Saultz (2017) mentioned that an effective headship promotes to teacher job satisfaction in any school system. Author also revealed that poor students achievement and high turnover are the results of low teacher job satisfaction, these issues shows significance of teachers job satisfaction. To assess levels of job satisfaction, there is need to consider some local strategies and validated methods.

(Memon, 2007) explained that geographical differences, gender inequality, deficiency of efficient human resources, poor physical facilities leads to poor functioning of educational system. According to Blackburn (2015) leaders of school have a considerable effect on the functioning of schools. As per the Ministry of Education (2009) of Pakistan the poor quality of present learning environment is patent from the fact that a lot of schools are missing basic 
facilities and infrastructure. Administrators have a very decisive place in the zone of education and they can make available the basic necessities for bringing quality in education and can lift education up to required level (Adebowale, 2014). According to the current situation an emerging issue in Pakistan is the excellence worth and quality in education. To achieve this goal, and for quality product, the education system needs some requisites to adopt (Saultz, A., \& Saultz, 2017).

\section{STEPS / SUGGESTIONS TO IMPROVE QUALITY - WHAT TO INVEST AND HOW TO INVEST}

It is believed that the quality in education is the basic need and fundamental right of every child but Government of Pakistan facing various problems while meeting this objective of delivering quality education.

To overcome these complications and challenges Government of Pakistan has adopted different approaches to resolve these issues and challenges.

\section{Steps Taken for Quality by the Government of Pakistan}

Reforms taken by Education Sector (2017) indicated the subsequent approaches for bringing quality at all stages of education:-

1. Benchmarking capabilities and skills

2. Step by step enhancement of curriculum

3. Teacher training and staff professionalism

4. Professional elaboration of organizers, principals and other staff members

4. Establishing of National Educational Assessment System (NEAS)

5. Improving the Training institutes of teachers

6. Formation of Evaluation Committee through associating incentives and grants

7. Intensification of non-salary budget for facilitation of educational infrastructure

8. District wise planning and application of plans

9. Community involvement and private plus public cooperation

10. Appointment of well qualified and skilled teachers.

11. Rise in pays of teachers

12. Provision of science laboratories in schools

13. Availability of science kits in schools

14. Computer education arrangements in schools

15. Launching a continuous internal evaluation system for the assessment of schools

16. Enhancing the budget for all levels of schools

According to Pakistan Economic Survey (2018) it is mentioned that government has carried out a lot of amendments to extend the quality of education and to advance the worth of public education in the Pakistan. This survey underlined the subsequent steps of government adopted for approaching quality education to good level:-

\section{Establishing National Education Assessment System}

This assessment system (NEAS) is launched by Government of Pakistan to assess and evaluate the quality of middle schools.

\section{Formulation of a National Textbook and Learning Materials Policy}

To prop up the enhancement of textbooks and curriculum and provision of textbooks at lower prices, a policy (NTLMP) National Textbook and Learning Materials Policy (2016) is launched.

\section{National Commission for Human Development (NCHD)}

(NCHD, 2015) is an agreement between private and public partnership to extend budgetary measures and to eradicate the gender inequity at secondary level.

\section{Strengthening of Teacher Training}

Many in service and pre service teacher training programs are ongoing to provide initiatives for untrained teachers.

\section{Technical and Vocational Education}

As per National Educational Policy (1998-2010) the excellence of schooling is associated with skilled and professional teachers, up to date curriculum, teaching methodologies, equipment and physical facilities and educational materials. Moreover this policy discussed that education quality is definitely associated with the instructions quality in classroom, especially in field of mathematics, science and languages.

\section{STEM EDUCATION}

It is important for STEM leaders to cultivate a leadership network consisting of principals, lead teachers, science department heads, and community leaders to implement science education reform at all levels of the school system. The locality should adopt a coherent strategy on STEM education. For example, the city authorities can issue a resolution on applying STEM in all schools with very specific objects. In the area of science curriculum, it is 
important for STEM leaders to develop and align curriculum, assessment, and instruction with national and state standards while meeting local needs. In the area of science teaching and learning, it is important for STEM leaders to build principals and teachers' capacities to provide instructional leadership in STEM education. In the area of professional development, it is important for science leaders to actively involve teachers in the decision making for professional development programs, curriculum changes, and other activities that affect their STEM practice. Moreover, Prime Minister, Imran Khan approved on Friday the launching of the STEM education project aimed at promoting science, technology, engineering and mathematics education in 400 higher secondary schools across the country to upgrade them as a STEM schools. The project would be the first of its kind in Pakistan.

\section{REFERENCES}

Adebowale Biodun, A. R. E. O. (2014). Women Involvement in Hand-Made Pottery and Marketing Concept Strategy. Journal of Economics and Sustainable Development. www.iiste.org.5(6), 150-159.

Ahmad, S (2009). Quality of Education. Retrieved on Dec 02, 2010. Retrieved from http://pakistantimes.net/2009/04/07/guest1.htm

Akram, H., Yingxiu Yang, N. A., \& Aslam, S. (2020). Factors Contributing Low English Language Literacy in Rural Primary Schools of Karachi, Pakistan. International Journal of English Linguistics, 10(6).

Alkhyeli, H. E., \& Ewijk, A. V. (2018). Prioritisation of factors influencing teachers' job satisfaction in the UAE. International Journal of Management in Education, 12(1), 1-24.

Ataliç, H., Can, A., \& Cantürk, N. (2016). Herzberg's motivation-hygiene theory applied to high school teachers in Turkey. European Journal of Multidisciplinary Studies, 1(4), 90-97.

Beaton, J. (1999). Performance indicators and quality management in the university: A critical review. Canadian Federation for the Humanities and Social Sciences, 1-54.

Beltman, S., Mansfield, C. F., \& Harris, A. (2016). Quietly sharing the load? The role of school psychologists in enabling teacher resilience. School Psychology International, 37(2), 172-188.

Blackburn, J. (2015). An evaluation of teacher morale in four elementary schools: The difference a school makes (Doctoral Dissertation, The National Loius University).

De Grauwe, A., \& Naidoo, J. P. (2004). School evaluation for quality improvement: An ANTRIEP report. Paris: International Institute for Educational Planning.

Dill, D. D. (2003). The 'Catch 22'of academic quality: Implications for universities and public policy. Public Policy for Academic Quality.

Farooq, R. A. (1994). Education system in Pakistan: Issues and problems. Asia Society for Promotion of Innovation and Reform in Education.

Gandhe, S. K. (2010). Quality assurance in open and distance learning in India. Open Praxis, 4(1), 26-32.

Government of Pakistan (2001). Technical group Meeting on devolution and decentralization, implementation for the education sector. Ministry of Education, Islamabad, Pakistan

Hanushek, E. A. (2002). Teacher Quality Edited by Lance T. Izumi and Williamson M. Evers, Stanford, CA: Hoover Institution Press. Accessed June 10, 2015

Hathaway, R. M. (2005). Education Reform in Pakistan: Building for the Future. Woodrow Wilson International Center for Scholars. One Woodrow Wilson Plaza, 1300 Pennsylvania Avenue NW, Washington, DC 20004-3027.

Hoodbhoy, P. (Ed.). (1998). Education and the state: Fifty years of Pakistan (Vol. 50). Oxford University Press, USA.

Hussain, I. (2005). Education, employment and economic development in Pakistan. Education Reform in Pakistan: Building for the Future, 33-45.

Khan, M. A. (1998). An appraisal of supervisory practices in the schools of district Attock. Unpublished thesis), University of Arid Agriculture, Rawalpindi, Pakistan, 33-45.

Leask, M. (2004). Using research and evidence to improve teaching and learning in the training of professionals-an example from teacher training in England.

Mayer, D. P., Mullens, J. E., \& Moore, M. T. (2001). Monitoring School Quality: An Indicators Report. Education Statistics Quarterly, 3(1), 38-44.

Memon, G. R. (2007). Education in Pakistan: The key issues, problems and the new challenges. Journal of Management and Social Sciences, 3(1), 47-55.

Ministry of Finance, Govt. of Pakistan (2013). Pakistan Economic Survey (2007-08). Islamabad

Mohanty, B. (2007). School administration and supervision. Deep and Deep Publications.Rajouri Garden, New Delhi, India

Parveen, K., Bao Phuc, T. Q., Shafiq, M., \& Wei, T. (2021). Identifying the administrative challenges encountered by the principals in low-performing public secondary schools of Faisalabad District, Pakistan. International Journal of Humanities and Innovation (IJHI), 4(1), 5-16.

Pounder, J. (1999). Institutional performance in higher education: Is quality a relevant concept?Quality Assurance in Education, 7(1/3), 156-163.

Qureshi, S. (2002). Decentralization to district level. Ministry of education, Islamabad, Pakistan. 
Saultz, A., \& Saultz, J. W. (2017). Measuring outcomes: lessons from the world of public education. The Annals of Family Medicine, 15(1), 71-76.

Shahzadi, R., \& Perveen, K. (2002). An Evaluation of new educational structure. Unpublished thesis). The University of Punjab, Lahore, Pakistan, 65-68.

Zafar, M. (2003). Fiscal devolution in education. Case study reflecting initial responses, 34-41.

Publisher's note: Science Impact Publishers remain neutral with regard to jurisdictional claims in published maps and institutional affiliations.

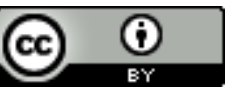

Open Access This article is licensed under a Creative Commons Attribution 4.0 International License, which permits use, sharing, adaptation, distribution and reproduction in any medium or format, as long as you give appropriate credit to the original author(s) and the source, provide a link to the Creative Commons license and indicate if changes were made. The images or other third-party material in this article are included in the article's Creative Commons license, unless indicated otherwise in a credit line to the material. If material is not included in the article's Creative Commons license and your intended use is not permitted by statutory regulation or exceeds the permitted use, you will need to obtain permission directly from the copyright holder. To view a copy of this license, visit https://creativecommons.org/licenses/by/4.0/.

(C) The Author(s) 2020 